\title{
Lynn Coady: Who Needs Books
}

\section{The University of Alberta Press, Edmonton, Alberta, Canada, 2016, 70 pp., \$10.95, Paperback, ISBN 978-1-77212-124-7}

\section{David M. Hetherington ${ }^{1}$}

Published online: 9 October 2020

(c) Springer Science+Business Media, LLC, part of Springer Nature 2020

This brief and superbly manufactured tome is a reprint of a lecture delivered by Ms. Coady in April 2015 at the University of Alberta's Canadian Literature Centre. Ms. Coady's lecture is a beautifully written, articulate argument for the enduring value of the book.

Having been in the book publishing business for more years than I care to confess, one becomes used to periodic prognostications of industry Cassandras forecasting the demise of the book and the lamentation that our culture is slowly but surely evolving into a society of techno-philistines. (Thank you, Ms. Coady for this wonderful description), barbarians of sort, whose definition of literature has degenerated to a Tweet or Instagram posting with Kim Kardashian as social media's answer to Jane Austen.

I am pleased to report that Ms. Coady articulately states her case that the printed word is alive and well and while we are dealing with inevitable and not so surprising challenges to the printed book, as a cultural institution the book is here to stay, whether the form be ebook, audio book, or that old stand-by, the printed book and the Internet be damned. The method of delivery may have changed to some significant extent (i.e. both the ebook and especially the phenomenal growth of audio books) but the book remains as a cultural fixture with no signs of its extinction on the visible horizon.

Ms. Coady does a splendid job of laying out the case that the cultural assault from the Internet is simply another iteration of the same "threat" that television was presented some 70 years ago and that like the so-called threat of television, the Internet is another storm that the book, regardless of its form, will successfully weather.

It should be noted that Ms. Coady's lecture was delivered in early 2015-some five years before the CoVid 19 pandemic that has raged through the globe for the past year and is still ravaging through the United States with no immediate end in

David M. Hetherington

david.hetherington@knk.com

1 Global Business Development, Books International, 22883 Quicksilver Drive, Dulles, VA 20166, USA 
sight. Her argument for the importance and enduring value of the book remains as credible today as it was in 2015 .

The world of book publishing has certainly been turned upside down with Barnes \& Noble in new hands and retail shelf space at a premium, Amazon leaving its roots in the book business behind to respond to a huge increase in the demand for touch free delivery of consumer products, independent bookstores being devastated by painful but necessary lock down measures and libraries of all shapes and sizes moving to digital delivery.

We are simply and unequivocally at a watershed moment that is reshaping the world at large and certainly the book publishing industry as we have come to know it. There is little doubt that the transition to digital has certainly accelerated as a result of CoVid 19 and the longer the pandemic lasts, the larger digital delivery's footprint will be. We are, to use a phrase from Ms. Coady's lecture, witness to a "tectonic shift" in the world of books, the final form of which remains to be seen.

The largely smooth migration from traditional office space to a work from home environment, the remarkable acceleration of the conversion to digital delivery by so many book publishers, and publishers actively working to establish and maintain direct relationships with their readers rather than ceding them to Amazon, all suggest an industry with resilience to spare and while there will undoubtedly be some casualties from CoVid 19, Ms. Coady's lecture is a welcome dose of much needed optimism for the survival of the book and for any student of the book publishing industry, it is not to be missed.

Publisher's Note Springer Nature remains neutral with regard to jurisdictional claims in published maps and institutional affiliations. 